\title{
Block Unit of Distance
}

National Cancer Institute

\section{Source}

National Cancer Institute. Block Unit of Distance. NCI Thesaurus. Code C111140.

A unit of measure to quantify the number of rectangular areas in a city surrounded by streets that the patient has traveled. 